\title{
Reconstrução de lábio inferior pós-mordedura equina: descrição de técnica e revisão anatômica
}

\section{Lower lip reconstruction after equine bite: technique description and anatomy review}

\author{
Fernando Passos Da \\ ROCHA $^{1}$ \\ Marcelo Wilson Rocha \\ AlmeIDA $^{2}$ \\ DJalma José Fagundes ${ }^{3}$ \\ Thiago Vial Costa ${ }^{4}$ \\ JefFerson André Pires 5
}

Trabalho realizado na Universidade Católica de Pelotas (UCPEL), Pelotas, RS; Instituto Ivo Pitanguy, Rio de Janeiro, RJ, Brasil; Universidade Federal de São Paulo - Escola Paulista de Medicina (UNIFESP - EPM), São Paulo, SP, Brasil; Universidade Federal da Bahia, Salvador, BA; Universidade Federal de Pelotas (UFPEL), Pelotas, RS, Brasil.

Artigo submetido no SGP (Sistema de Gestão de Publicações) da RBCP.

Artigo recebido: 6/7/2009 Artigo aceito: 12/8/2009

\begin{abstract}
RESUMO
Introdução: A cirurgia reconstrutiva do lábio, seja superior ou inferior, possibilita sua reconstrução por meio de uma variedade de técnicas cirúrgicas. Nessas reconstruções, é importante avaliar as características do tecido (cor da pele, textura), o qual sempre que possível deve ser utilizado próximo ao local da lesão, para fornecer o melhor resultado estético e funcional possível. Relato do Caso: O presente trabalho tem como objetivo descrever a técnica de Bernard-Burow para reconstrução de lábio inferior, e revisar a anatomia do terço inferior da face, por meio do relato de caso de um paciente que foi mordido por um cavalo e teve avulsão de lábio inferior e porção mentoneana e submentoneana da face.
\end{abstract}

Descritores: Lábio/cirurgia. Lábio/lesões. Mordeduras e picadas. Traumatismos faciais. Ferimentos e lesões.

\begin{abstract}
Background: The reconstructive surgery of the lip, upper or lower, presents a variety of techniques and procedures. In reconstructive surgery of lip is important to evaluate the characteristics of tissue (skin color, texture), which wherever possible should be used near the site of injury to provide the least morbidity and best tissues in colors and texture. Case Report: This article aims to describe the Bernard-Burow technique for reconstruction of lower lip, and review the anatomy of the lower third of the face, through the case report of a patient who was bitten by a horse and had avulsion of lower lip and mentoniane portion of the face.
\end{abstract}

Keywords: Lip/surgery. Lip/injuries. Bites and stings. Facial injuries. Wounds and injuries.

\section{INTRODUÇÃO}

A cirurgia reconstrutiva do lábio, seja superior ou inferior, permite sua reconstrução por meio de uma variedade de técnicas e procedimentos cirúrgicos. As reconstruções de lábio são procedimentos frequentes e sua dificuldade está relacionada ao tamanho e à localização da perda de substância. A reparação da perda total de lábio envolve procedimentos mais complexos, que podem gerar deformidades em outras regiões da face.

Podemos citar como as técnicas precursoras da reconstrução de lábio inferior o retalho quadrangular de Dieffenbach $^{1}$; Burow ${ }^{2}$, com as ressecções de triângulos de pele e subcutâneo, laterais aos sulcos nasolabiais; e Bernard ${ }^{3}$, com o avanço de retalhos laterais.

Dessas técnicas citadas derivaram outras conhecidas, como a de Scymanowski ${ }^{4}$, Webster et al. ${ }^{5}$, Karapandzik ${ }^{6}$,

1. Professor Assistente do Departamento de Cirurgia da Universidade Católica de Pelotas (UCPel), Membro Associado da Sociedade Brasileira de Cirurgia Plástica, Pelotas, RS, Brasil.

2. Residente de Cirurgia Plástica no Instituto Ivo Pìtanguy, Rio de Janeiro, RJ, Brasil.

3. PhD; Professor Associado do Departamento de Cirurgia da Universidade Federal de São Paulo - Escola Paulista de Medicina (UNIFESP), São Paulo, SP, Brasil.

4. Residente de Cirurgia Plástica da Universidade Federal da Bahia, Salvador, BA, Brasil.

5. Acadêmico de Medicina da Universidade Federal de Pelotas (UFPel), Pelotas, RS, Brasil. 
Fujimori" com os "retalhos em portão", Barron \& $\mathrm{Saad}^{8}$, com o retalho miocutâneo do músculo platisma, entre outras.

O último século é considerado um marco ou o mais importante pelo avanço tecnológico e, consequentemente, pelo refinamento dos princípios acima mencionados. Como exemplo, cita-se Karapandzic ${ }^{6}$, que introduziu o retalho de avanço pediculado mioneurovascular, e Harii Ohmori, que realizou a transferência de tecido livre microvascular.

O presente trabalho tem como objetivo descrever a técnica de Bernard-Burow para reconstrução de lábio inferior, e revisar a anatomia do terço inferior da face, por meio do relato de caso de um paciente que foi mordido por um cavalo e teve avulsão de lábio inferior e porção mentoneana e submentoneana da face.

\section{Revisão Anatômica}

O conhecimento da anatomia do terço inferior da face é necessário para se indicar a técnica adequada na reconstrução do lábio inferior. $\mathrm{Na}$ parte superficial, identificase o sulco nasolabial, colunas do filtro, sulco do filtro, sulco labiomental, arco do cupido, tubérculo, comissura labial, vermelhão do lábio e linha branca do lábio superior (Figura 1).

O componente esfinctérico do lábio é representado pelas fibras circulares ou semicirculares do músculo orbicular da boca, auxiliado pelo músculo mental. O componente dilatador é formado pelas fibras radiais de vários músculos faciais: levantador do lábio superior e da asa do nariz, levantador do lábio superior, zigomático maior, bucinador, depressor do ângulo da boca, depressor do lábio inferior, levantador do ângulo da boca (Figura 2).

A irrigação é feita pela artéria facial, cujas artérias labial superior e inferior se anastomosam. A linfa é drenada para os linfonodos submandibulares e submentais (Figura 3). A inervação sensitiva do lábio superior é realizada pelo nervo infraorbital e a do lábio inferior, pelo nervo mental. A inervação motora é feita pelo nervo facial (Figura 4).

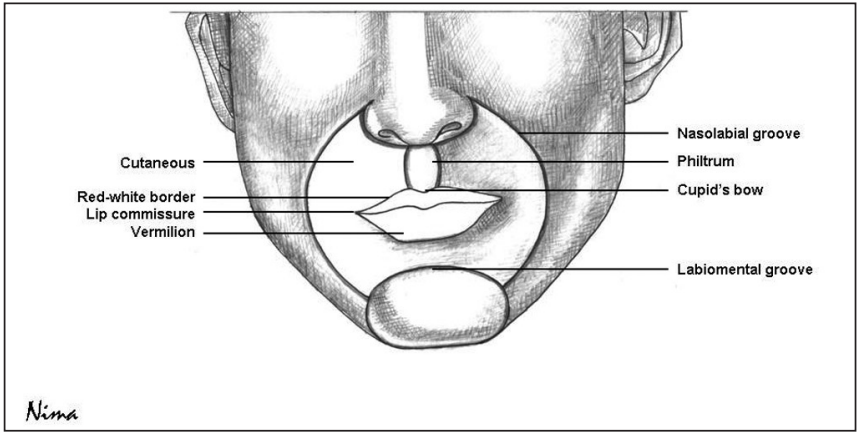

Figura 1 - Anatomia superficial do terço inferior da face.

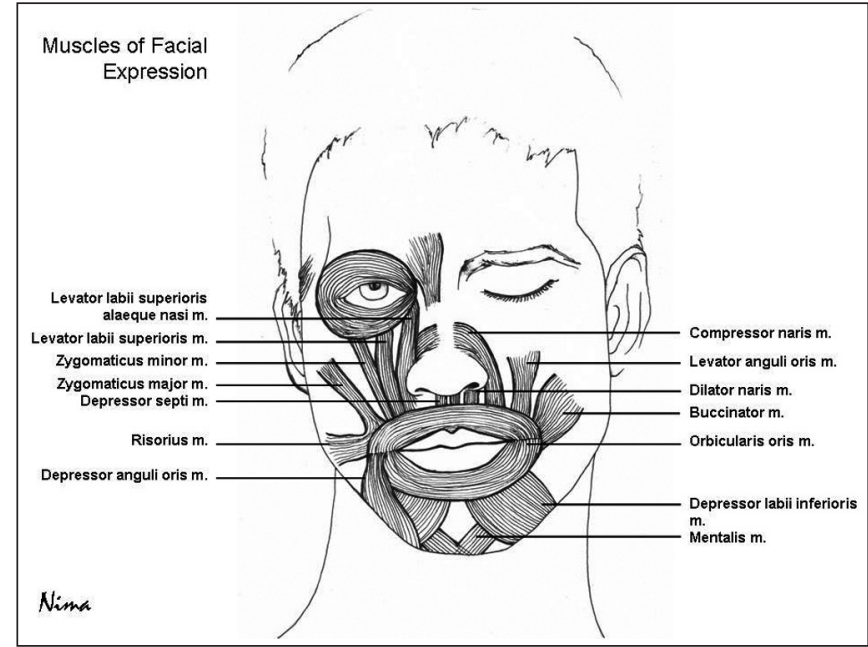

Figura 2 - Músculos do terço inferior da face.

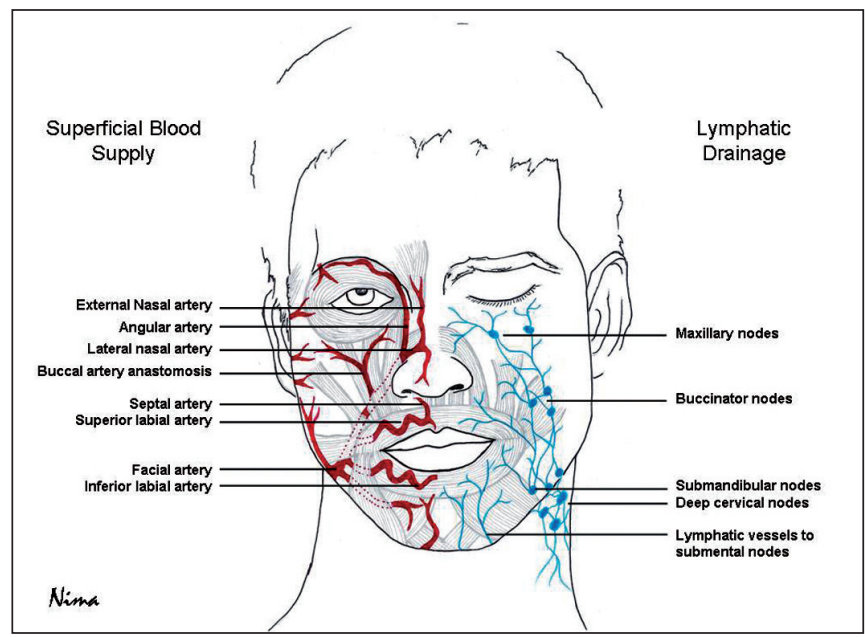

Figura 3 - Irrigação e drenagem linfática do terço inferior da face.

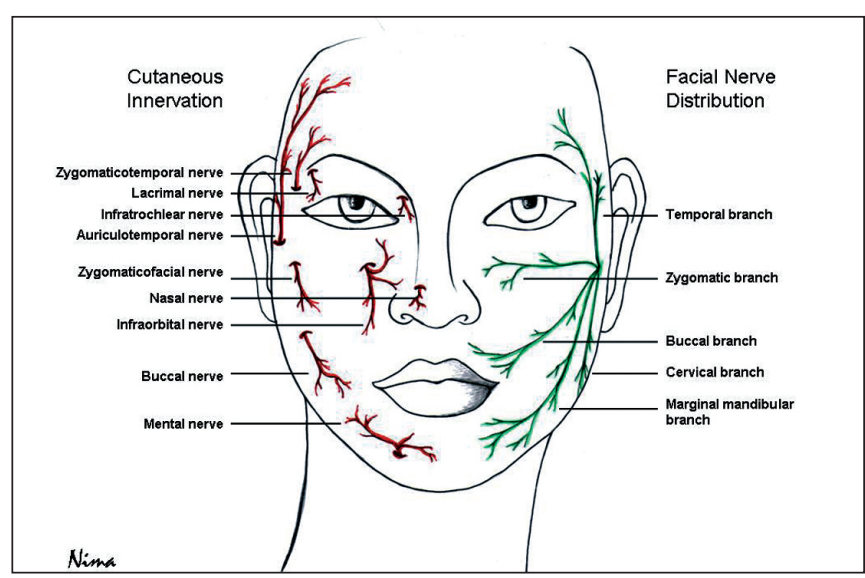

Figura 4 - Inervação sensitiva e motora do terço inferior da face. 


\section{RELATO DO CASO}

Paciente de 30 anos, sexo masculino, negro, trabalhador rural, vítima de mordida de cavalo da raça Crioula, foi atendido em caráter de urgência, pelo serviço de Cirurgia Plástica da Santa Casa de Misericórdia de Pelotas (SCMPel), com importante avulsão de lábio inferior e região mentoneana e submentoneana da face (Figura 5).

$\mathrm{O}$ paciente foi operado sob anestesia geral, sendo respeitadas as técnicas de antissepsia e assepsia. A técnica de reconstrução utilizada foi a de Bernard-Burow. Esta técnica consiste na ressecção de dois triângulos, englobando toda a espessura do lábio superior (exceto uma faixa de $1 \mathrm{~cm}$ de mucosa, que fica presa na margem inferior e é evertida para refazer o vermelhão). $\mathrm{O}$ afrontamento direto dos bordos desses triângulos produz um avançamento de igual dimensão do lábio inferior no sentido látero-medial.

No planejamento cirúrgico, primeiramente fizemos as demarcações. Em tracejado, assinalamos a área a ser ressecada. As duas faixas em branco, nos triângulos superiores, correspondem à parte de mucosa que é conservada para reconstituir o vermelhão (Figura 6A). Completada a ressecção, observa-se, no hemilábio direito do desenho a sutura da mucosa jugal ao bordo cutâneo, refazendo, assim, o vermelhão (Figura 6B). Na Figura 6C, observa-se o término das suturas.

Quanto ao paciente do relato, nota-se que não foi necessário demarcar o triângulo inferior, pois a parte avulsionada só necessitou alguns ajustes para ser aproximada adequadamente (Figura 7). A rafia da mucosa foi feita com poliglactina 910 (Vicryl® 4.0). A musculatura adjacente à mucosa foi aproximada com poliglactina 910 (Vicryl ${ }^{\circledR}$ 3.0). A sutura da pele foi feita utilizando fio de poliamida 3.0 (mononylon ${ }^{\circledR} 3.0$ ). Terminado o procedimento, foi realizado curativo cirúrgico de rotina.

O defeito ocasionado pela mordida do cavalo foi corrigido com sucesso. Apesar da gravidade da lesão, e da perda de músculos importantes de região metoneana e submentoneana, obteve-se resultado bastante satisfatório, tanto no aspecto estético como funcional (Figura 8). Não houve complicações pós-operatórias.

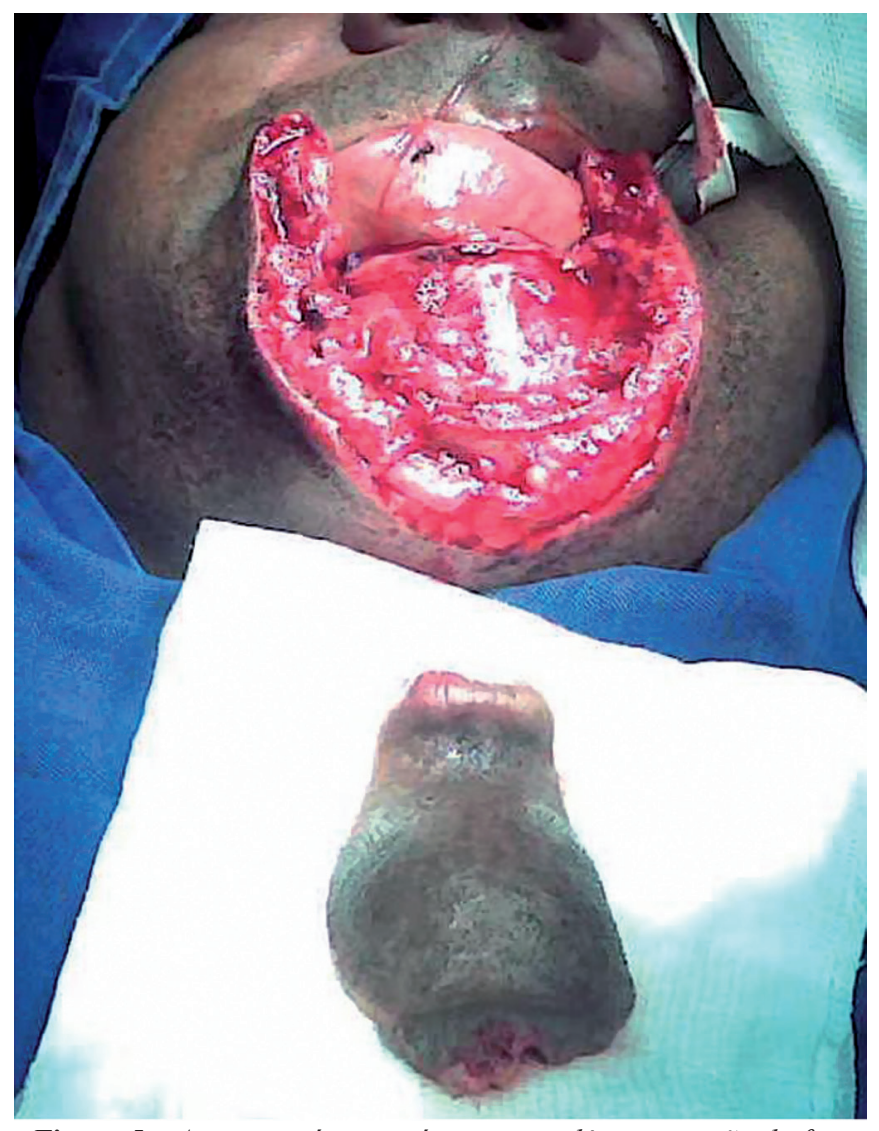

Figura 5 - Aspecto pré-operatório; em evidência, porção da face que foi avulsionada pela mordida.

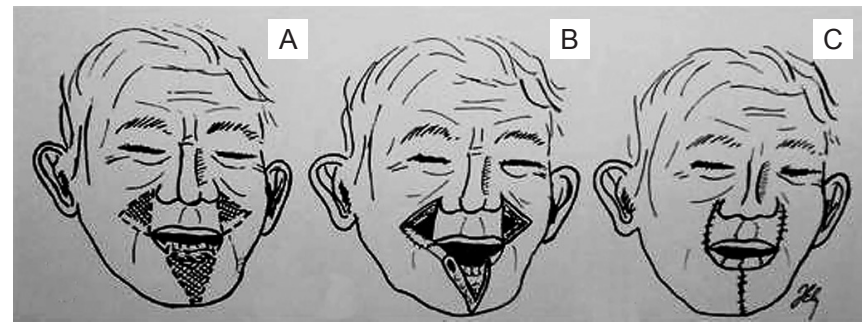

Figura 6 - Desenho esquemático da técnica de Bernard-Burow. A: Demarcação em pontilhado da área que será ressecada; $\boldsymbol{B}$ : Completada a ressecção; $\boldsymbol{C}$ : Terminada a sutura.

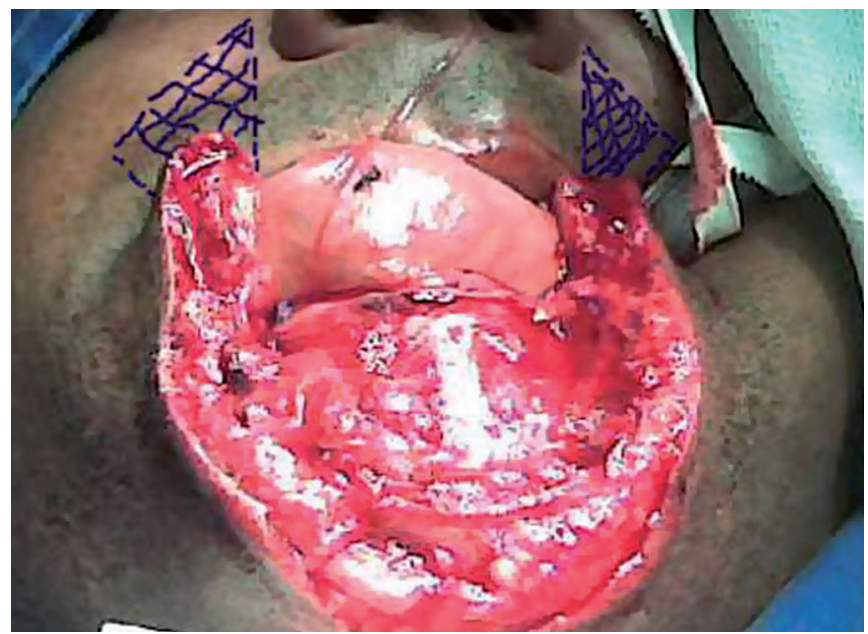

Figura 7 - Demarcação dos triângulos superiores no paciente. 


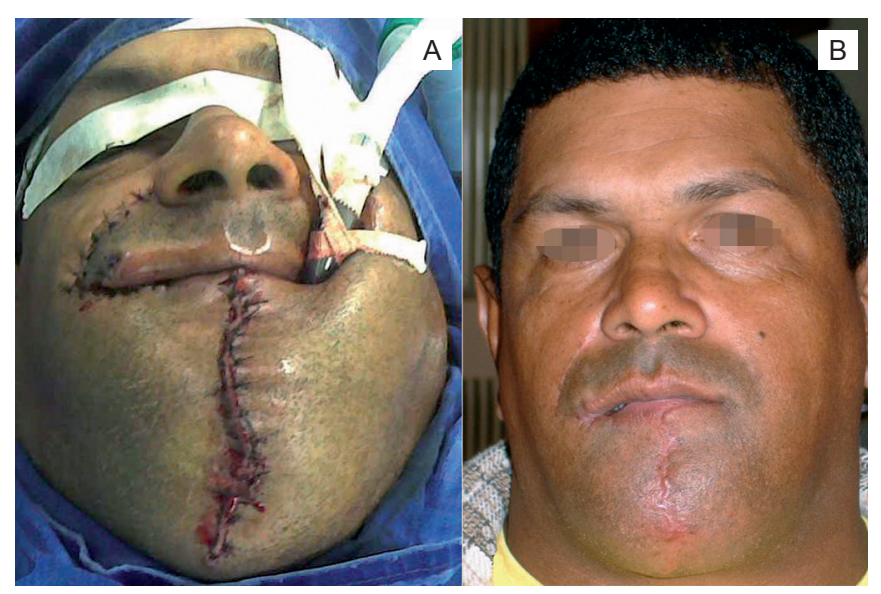

Figura 8-Resultados. A: Pós-operatório imediato. B: Pós-operatório de 4 meses.

\section{DISCUSSÃO}

Os lábios desempenham um papel fundamental na expressão facial, na fala, na alimentação e até mesmo para expressar sentimentos, como num beijo. Nas reconstruções labiais, é importante avaliar as características dos tecidos (cor da pele, textura), o qual sempre que possível deve ser utilizado da proximidade do local da lesão, para fornecer o mínimo de morbidade e melhor funcionalidade e resultado estético possível.

No caso de nosso paciente, foi escolhida a técnica de Bernard-Burow para reconstruir o lábio inferior, pois a região e o formato da área lesada quase equivalem ao triângulo inferior, que deve ser ressecado na técnica citada. Além disso, essa técnica é indicada em situações em que novos tecidos de lábio são necessários, como no caso relatado.

Entre as desvantagens dessa técnica estão a recuperação incompleta da sensibilidade e motricidade, a pequena alteração da cor do vermelhão e, em alguns casos, incontinência oral.

A técnica de Bernard-Burow é indicada para grandes perdas de substância de lábio inferior. A proximidade dos retalhos faz com que o procedimento seja de baixa morbidade e confira ao lábio e ao tecido adjacente semelhante cor e textura. A principal desvantagem está em alguma perda de sensibilidade e motricidade da região operada. Contudo, ela confere ao paciente ótimo resultado estético e funcional, com consequente melhora da autoestima do paciente.

\section{REFERÊNCIAS}

1. Dieffenbach JF. Chirurgische Erfahrungen, besonders ueber die Wiederherstellung Zerstoerter Theile des menschlichen Koerpers nach neuen methoden. Bedim: TC.F. Enslin;1829. p.34-8.

2. Burow A. Zur Blepharoplastik. Monatsschr. Med Augenheilkd Chir. 1838;1:57-61.

3. Bernard C. Cancer de la levre inferieur opere par un procede nouveau. Bull Soc Chir Paris. 1853;3:357-60.

4. von Scymanowski J. Zur plastichen Chirurgie. Vrtljschr Prakt Heilk. 1858;60:152-7.

5. Webster RC, Coffey R, Kelleber RE. Total and partial reconstruction of the lower lip with innervated muscle-bearing flaps. Plast Reconstr Surg. 1960;25(3):360-71.

6. Karapandzik M. Reconstruction of lip defects by local arterial flaps. $\mathrm{Br}$ J Plast Surg. 1974;27(1):93-7.

7. Fujimori R. «Gate flap» for the total reconstruction of the lower lip. $\mathrm{Br}$ J Plast Surg. 1980;33(3):340-5.

8. Barron IN, Saad MN. Platysma musculocutaneous flap to the lower lip. In: Strauch B, Vasconez LO, Hall-Findlay EJ, eds. Grabbs encyclopedia of flaps. vol. 1. Boston:Little, Brown \& Co;1990. p.989-93. 